\title{
Uma montagem de câmara de nuvens por difusão para museus de ciências e laboratórios didáticos ${ }^{+*}$
}

\author{
Osmar Henrique Moura da Silva ${ }^{1}$ \\ Carlos Eduardo Laburúl \\ Departamento de Física \\ Universidade Estadual de Londrina \\ Londrina - PR
}

\section{Resumo}

Câmaras de nuvens são interessantes experimentos onde se evidenciam traços produzidos por partículas subatômicas. Na versão de difusão para fins educacionais e demonstrativos, a necessária refrigeração da parte inferior da câmara tem sido popularmente estabelecida com o uso de gelo seco, nitrogênio líquido ou dispositivos termoelétricos (pastilhas Peltier). Este trabalho sugere uma proposta diferenciada de montagem, de custo relativamente baixo, cujo sistema de refrigeração por ciclo de compressão se mostra vantajoso nos seguintes aspectos: ampla área de observação de traços; automatização da refrigeração sem manutenção; duração das demonstrações por horas. Tal proposta de câmara é conveniente para exposição em ambientes de educação não formal, como museus de ciências e similares, procurando, nesse sentido, contribuir ao levar em conta os altos valores de câmaras de nuvens comercializadas com essas características. A proposta pode ser também aproveitada em laboratórios didáticos de universidades e demais interessados.

Palavras-chave: Proposta de Montagem; Câmara de Nuvens de Difusão; Museus de Ciências e Similares; Laboratórios Didáticos.

\footnotetext{
${ }^{+}$A construction diffusion cloud chamber for science museums and didactic laboratories

* Recebido: dezembro de 2018. Aceito: junho de 2019.

${ }^{1}$ E-mails: osmarh@uel.br; laburu@uel.br
} 


\begin{abstract}
Cloud chambers are interesting experiments where traces produced by subatomic particles are evidenced. In the diffusion version for educational and demonstrative purposes, the necessary cooling of the chamber has been popularly established with the practice of dry ice, liquid nitrogen or thermoelectric devices (Peltier pellets). This work suggests a differentiated proposal of construction that has relatively low cost and advantageous refrigeration system by cycle of compression that show advantage in the following aspects: wide area of observation of traces; automation of maintenance-free cooling; duration of demonstrations for hours. Such a camera is convenient for exposure in non-formal education environments, such as science museums and simlar spaces, looking for to contribute by taking into account the high costs of cloud chambers in the marketed with these similar characteristics. The proposal can also be used in didactic laboratories of universities and other interested parties.
\end{abstract}

Keywords: Proposal Construction; Difusion Cloud Chamber; Science Museus; Didactic Labs.

\title{
I. Introdução
}

A Câmara de Nuvens constituiu-se importante instrumento ao estudo da radiação e partículas elementares, sendo o primeiro detector capaz de evidenciar traços produzidos por partículas subatômicas. Esses traços são observados em duas distintas versões de câmaras: uma operando por "difusão"; outra operando por "expansão". A esta última, em termos históricos, é que se atribui a criação de tal instrumento ao físico escocês C. T. R. Wilson, cujo protótipo inicial funcionou devido ao comportamento dos gases em mudanças bruscas de pressão

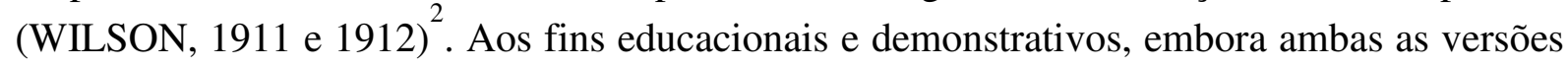
possam ser reproduzidas com base em orientações na internet, o presente trabalho propõe a montagem de uma versão de difusão diferenciada. Nas divulgadas montagens da versão de difusão com custos consideravelmente baixos, as típicas refrigerações da parte inferior da câmara ${ }^{3}$, em grande parte, foram realizadas por meio do uso prático de gelo seco (STONG, 1959; PINHEIRO, $2015^{4}$ ), e ainda podendo ser substituído por nitrogênio líquido. Já diante da dificuldade de os professores usarem a câmara nas aulas em razão de essas substâncias não

\footnotetext{
2 A versão por difusão surgiu posteriormente (LANGSDORF, 1936).

${ }^{3}$ Funcionando com temperaturas abaixo de $-30^{\circ} \mathrm{C}$ (ibid.).

4 <https://www.youtube.com/watch?v=KsPIFFEiCc8>.
} 
serem de fácil obtenção assim como de se manterem por muito tempo nas escolas, Kamata e Kubota (2012) propuseram uma alternativa com um específico gel que "preserva" a refrigeração por quase 20 minutos, após retirado de um freezer doméstico, viabilizando inúmeras repetições da demonstração ao reutilizar o produto . Outra possibilidade, que se destaca por eliminar quaisquer manutenções referentes à refrigeração, está no uso de pastilhas termoelétricas (Peltier) (MECONAL, 1986), tipo de montagem mais detalhada e com restrita área de observação, em geral, próxima dos $100 \mathrm{~cm}^{2}$. Comercialmente, dada a possibilidade de automação da refrigeração via pastilhas Peltier, alguns fabricantes negociam pequenas e portáteis câmaras de nuvens de difusão com preços entre $\mathrm{R} \$ 11000,00^{6}$ a $\mathrm{R} \$ 45000^{7}$, dependendo dos acessórios utilizados ${ }^{8}$. Por contraste, vale exemplificar outro modelo, ainda mais sofisticado e caro de câmara de difusão, fabricado em dois tamanhos ${ }^{9}$, cujo sistema de refrigeração por ciclo de compressão difere dos mencionados e beneficia: ampla área de observação de traços; automatização da refrigeração sem manutenção; duração das demonstrações por horas.

Baseado nessas ponderações, as vantagens do último modelo são características importantes que prontificam sua adaptação num salão de exposição de ambientes de educação não formal, como museus de ciências e similares, que aderem uma perspectiva de aprendizagem por livre escolha (DIERKING, 2005) pela qual os mais variados visitantes, independentemente do nível escolar ou idade, são designados eles próprios a livremente interagirem com o que lá se programa ao entretenimento e simulação (CHELINI \& LOPES, 2008, os. 228 e 235; VALENÇA, 2006, p. 333). Todavia, em função dos elevados custos, o presente trabalho apresenta uma proposta de montagem de câmara de nuvens de difusão com custo bem reduzido e que atende as conveniências citadas. A proposta não envolve uso de gelo seco, nitrogênio líquido, gel específico, e nem pastilhas termoelétricas Peltier, mas um sistema de refrigeração por ciclo de compressão. Logo, espera-se contribuir com uma alternativa útil àqueles profissionais atuantes em pequenos e médios museus e centros de ciência, estando em fase inicial de elaboração ou não ${ }^{10}$, que perseguem a meta de continuamente aprimorarem e ampliarem seus

\footnotetext{
${ }^{5}$ A demonstração proposta pelos autores ocorre num pequeno copo de vidro caseiro, cabendo uma fonte emissora de radiação alfa (ibid., p. 432).

$6<$ http://www.leermiddelen.be/en/cloud-chamber-wpeltier-cooling----phywe---09043-01>.

$7<$ http://nadascientific.com/science_education/peltier-cloud-chamber.html>.

${ }^{8}$ Que incluem até variadas fontes radioativas para maiores estudos, apesar de, como é sabido, câmaras de nuvens de difusão com razoáveis áreas para observação permitem facilmente visualizar traços provenientes da radiação de ocorrência natural.

${ }^{9}$ Conforme recente pesquisa de preço, o modelo menor e mais barato, com área de observação de $45 \times 45 \mathrm{~cm}$, é vendido por 37000 euros. <https://www.phywe.com/en/diffusion-cloud-chamber-45-x-45-cm-pj45.html>. O modelo maior, com área de observação de $80 \quad$ x80 cm, sai por 114000 euros. $<$ https://www.phywe.com/en/diffusion-cloud-chamber-80-x-80-cm-pj-80-230-v.html>. Obs.: valores para importação direta.

10 A respeito da crescente expansão desses ambientes no Brasil, tem-se avaliado uma quantia relativamente baixa ao atendimento de mais de cinco mil municípios (DENTILLO, 2013), além do insuficiente investimento que permanece nesse sentido (ibid.).
} 
acervos de equipamentos interativos. A proposta também é oportuna para emprego em laboratórios didáticos de escolas, universidades e demais interessados.

\section{Proposta de montagem e uso no ambiente de educação não formal}

Descreve-se aqui parte da experiência de um projeto de inserções de tecnologias educacionais em um museu de ciências ainda em fase inicial de desenvolvimento. O procedimento de construção da câmara de nuvens e os materiais utilizados seguem discutidos nesta seção. Devido à variedade de itens e detalhes procedimentais, pretende-se orientar sua construção em subseções separadas denominadas: Câmara de nuvens e o sistema de refrigeração; Parte eletrônica; Preparação final e aplicação. A aplicação descrita nesta última subseção refere-se à inserção da proposta num pequeno museu de ciências, incluindo algumas reflexões sobre os modos de implementação e aperfeiçoamento do protótipo de câmara desenvolvido, na medida em que um direcionamento nesse sentido fica a critério da equipe pedagógica local.

\section{II.1 Câmara de nuvens e o sistema de refrigeração}

Uma câmara de nuvens de difusão constitui-se num recipiente transparente, de 10 a $15 \mathrm{~cm}$ de altura, no qual se estabelece uma diferença de temperatura entre as superfícies superior e inferior: a de cima podendo estar em temperaturas ambientes de clima tropical e a de baixo numa temperatura menor que $-30{ }^{\circ} \mathrm{C}$. Assim, o álcool (em geral isopropílico ou etílico) ${ }^{11}$, depositado num feltro fixo no teto da câmara, evapora e desce lentamente em direção à superfície inferior mais fria, na medida em que a câmara vai se saturando desse vapor. Nesse sistema, uma partícula carregada, que por ele passar, ionizará o vapor supersaturado induzindo sua condensação em gotículas de álcool, formando um traço visível do trajeto. Cabe ainda, para um melhor surgimento/identificação de traços, a corriqueira diferença de potencial interna aplicada entre o fundo metálico da câmara e uma grade paralela este fundo localizada no topo da mesma, de forma a criar um campo elétrico aproximadamente homogêneo e direcionado para cima (de modo a conduzir íons positivos para baixo).

O sistema de refrigeração aqui empregado utilizou peças da tubulação de um bebedouro de pressão (condensador e evaporador), substituindo seu compressor original por um compressor de freezer de $1 / 4 \mathrm{Hp}$, no qual se trocou o usual gás refrigerante R-134 pelo R$404 \mathrm{~A}^{12}$, que atinge menores temperaturas. Conforme se nota na Fig. 1A, arquitetou-se um formato espiral na serpentina do evaporador para, acima dele, uma chapa de cobre de $20 \times 15$ $\mathrm{cm}$ com $2 \mathrm{~mm}$ de espessura fosse soldada (Fig. 1B), que é por ele resfriada a uma temperatura

\footnotetext{
11 Conforme Pinheiro (2015, p. 521), “O álccol etílico também pode ser usado, mas recomenda-se o uso de álcool isopropílico pela sua pureza. Com uma menor quantidade de água evita-se a formação de cristais de gelo. Assim, um líquido relativamente puro apresenta uma boa capacidade de evaporação à temperatura ambiente".

$12 \mathrm{O}$ custo de um vasilhame de $425 \mathrm{~g}$ do gás sai por volta de 40 reais no mercado.
} 
média de $-45^{\circ} \mathrm{C}^{13}$. É preciso salientar que esta temperatura na chapa é alcançada ainda por dois fatores: um ventilador soprando no condensador do sistema; uso de pasta térmica para preencher espaços entre a serpentina espiral do evaporador e a chapa de cobre, no intuito de melhorar a condução térmica destes últimos.

A chapa de cobre (Fig. 1B), pintada de preto (Fig. 1D), tem toda a parte lateral e abaixo dela, composta da serpentina espiral e pasta térmica, revestida de uma camada de isopor de $2 \mathrm{~cm}$ de espessura para típico isolamento térmico. A Fig. 1C apresenta a tampa de vidro removível da câmara voltada para cima, de modo a observar umas adaptações ali fixadas com silicone, quais sejam: uma espuma para depósito de álcool de $1 \mathrm{~cm}$ de espessura, com cerca de $2 \mathrm{~cm}$ percorrendo toda a borda da tampa; 2 pedaços de PCV, por onde são passados fios paralelos conectados a um fio que atravessa determinado furo na tampa de vidro (fio este que se conecta ao negativo do circuito multiplicador de tensão apresentado na Fig. 2 mais à frente).

Providenciando a devida suspensão da chapa de cobre em posição imóvel ${ }^{14}$ e nivelada a uma altura avaliada de acordo com os arranjos dimensionados na montagem, a câmara de vidro de $12 \mathrm{~cm}$ de altura pode então ser montada sobre a chapa (Fig. 1 D). Na Fig. 1D, há o emprego de uma lâmpada fluorescente de $23 \mathrm{~cm}$ de comprimento (retirada de scanner), situada numa lateral maior e pouco acima da base da câmara, para iluminar as gotículas de álcool que se formam mais no fundo, permitindo a visualização de traços; iluminação esta que tem intensidade ajustável na montagem.

Na subseção seguinte, apresentam-se os detalhes do circuito eletrônico desenvolvido para automatização e funcionamento desta câmara de nuvens, pelo qual se possibilita o acionamento por aperto de botão com tempo de funcionamento controlado do sistema de refrigeração, da alta voltagem (Vcc) estabelecida no interior da câmara, e do ajuste da intensidade de iluminação.

\section{II.2 Parte eletrônica}

Conforme a Fig. 2, a área maior demarcada por traço pontilhado engloba os componentes num circuito que estabelece uma programação de acionamento da demonstração ao aperto de botão (push-button) e, após um tempo estipulado (no caso de cerca de 50 $\operatorname{tos}^{15}$ ), cessá-la automaticamente. A tabela 1 exibe a totalidade dos componentes referentes a esta área maior demarcada por traço pontilhado.

\footnotetext{
${ }^{13}$ Medida realizada com termômetro infravermelho direcionado nesta superfície quando a câmara está funcionando.

${ }^{14}$ Para isso, utilizaram-se aqui 4 hastes metálicas verticalmente fixadas em cantos da chapa seguindo até a base da caixa que sustenta o compressor (Fig. 1D).

15 Pode-se alterar esse tempo modificando os valores do resistor 1,2 M $\Omega$ e/ou do capacitor de $2200 \mu \mathrm{F}$. Aplicativos disponíveis na internet simulam o tempo desejado nessas modificações. Ex.: $<$ https://play.google.com/store/apps/details?id=it.android.demi.elettronica\&hl=pt_BR>. Último acesso: 16 de abril de 2008.
} 


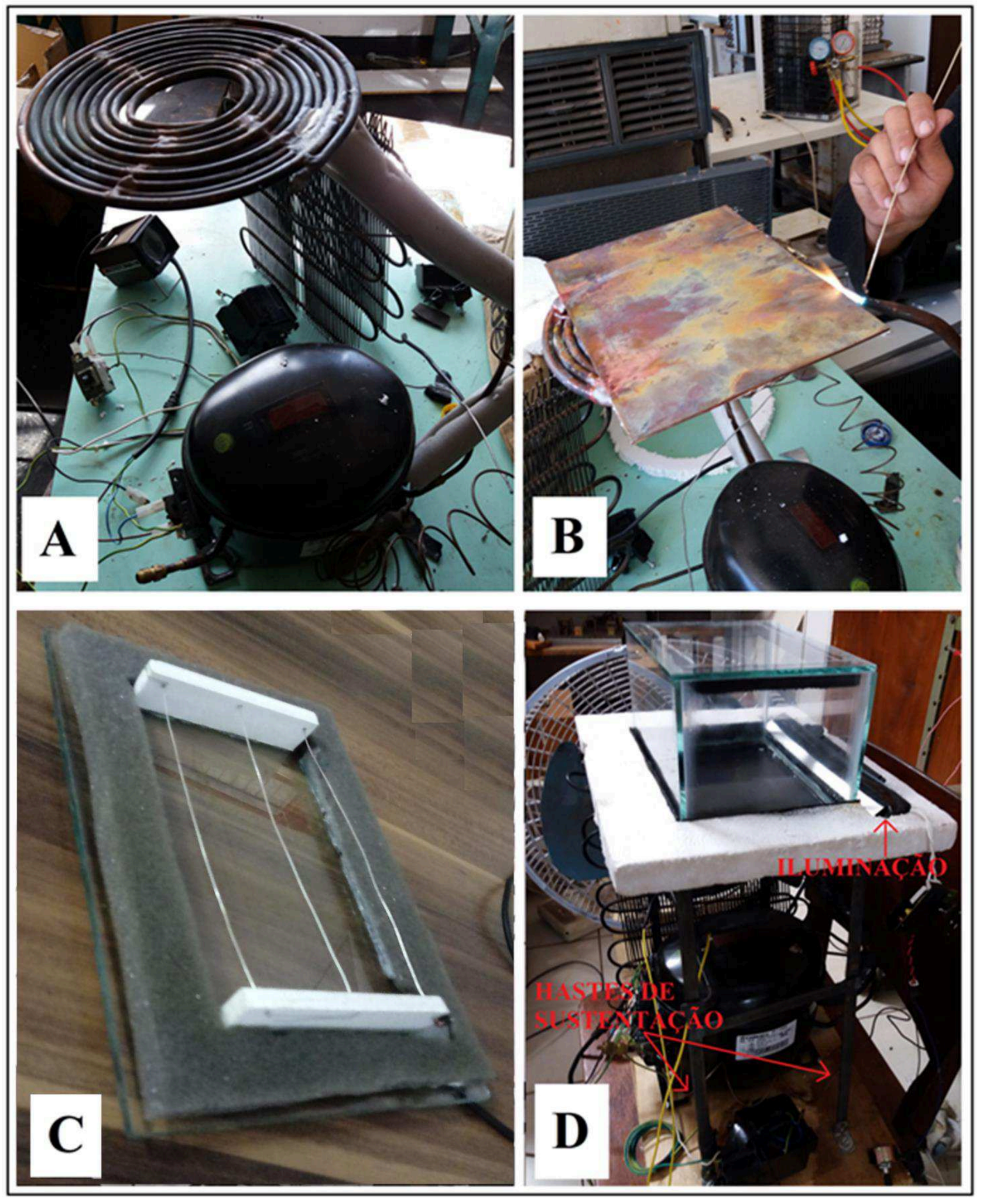

Fig. 1 -Câmara de nuvens e os detalhes da refrigeração. Fonte: autores. 
Tabela 1 - Totalidade de componentes empregados na área maior demarcada por traço pontilhado da Fig. 2.

\begin{tabular}{|c|c|}
\hline Componente & Quantidade \\
\hline Diodo IN 4007 & 2 \\
\hline Capacitor de $1000 \mu \mathrm{F}$ de $16 \mathrm{~V}$ & 1 \\
\hline Resistor de $1,2 \mathrm{M} \Omega$ & 1 \\
\hline Capacitor de $2200 \mu \mathrm{F}$ de $16 \mathrm{~V}$ & 1 \\
\hline CI 555 & 1 \\
\hline Resistor de $22 \mathrm{~K} \Omega$ & 1 \\
\hline Resistor de $1 \mathrm{~K} \Omega$ & 1 \\
\hline Capacitor de $1 \mathrm{nF}$ de $16 \mathrm{~V}$ & 1 \\
\hline Capacitor de $10 \mathrm{nF}$ de $16 \mathrm{~V}$ & 1 \\
\hline Transistor $\mathrm{BC} 548$ & 1 \\
\hline Relé de $12 \mathrm{~V}$ & 1 \\
\hline
\end{tabular}

Fonte: autores.

A propósito, por uma breve comparação desse dispositivo eletrônico com o popular Arduino, um projeto de automação com esse último, além de compreender conhecimentos básicos de linguagem de programação, de eletrônica ${ }^{16}$ e de desenvolvimento de algoritmos (cujo domínio, porém, não deixa de ser um ponto positivo), mostrou-se aqui com um custo maior que o desse dispositivo na Fig. 2 (referente à área maior demarcada por traço pontilhado), segundo recente pesquisa de preço.

Há um transformador (entrada de $127 \mathrm{~V}$ e saída de $12 \mathrm{~V}$ ) que alimenta esse circuito que, por sua vez, quando pressionado o botão push-button (NA), ativa temporariamente a fonte de tensão $(12 \mathrm{~V})^{17}$, o compressor de refrigeração18, e o circuito multiplicador de tensão, cujos componentes na área menor demarcada com traço pontilhado da Fig. 2 seguem especificados na Tabela 2.

\footnotetext{
16 Aliás, o uso de Arduino nessas funções também inclui a adaptação particular de um simples circuito eletrônico a ser montado.

17 Observa-se no diagrama esquemático um potenciômetro (50 $\Omega$ ) adaptado para ajuste da intensidade de iluminação da lâmpada fluorescente.

18 Simultaneamente, um ventilador aqui adaptado também é acionado para melhor refrigerar a grade do condensador.
} 
Tabela 2 - Componentes empregados na área menor demarcada por traço pontilhado da Fig. 2.

\begin{tabular}{|c|c|}
\hline Componente & Quantidade \\
\hline Diodo IN 4007 & 4 \\
\hline Capacitor de $220 \mu \mathrm{F}$ de $630 \mathrm{~V}$ & 4 \\
\hline Resistor de $20 \mathrm{M} \Omega$ & 1 \\
\hline
\end{tabular}

Fonte: autores.

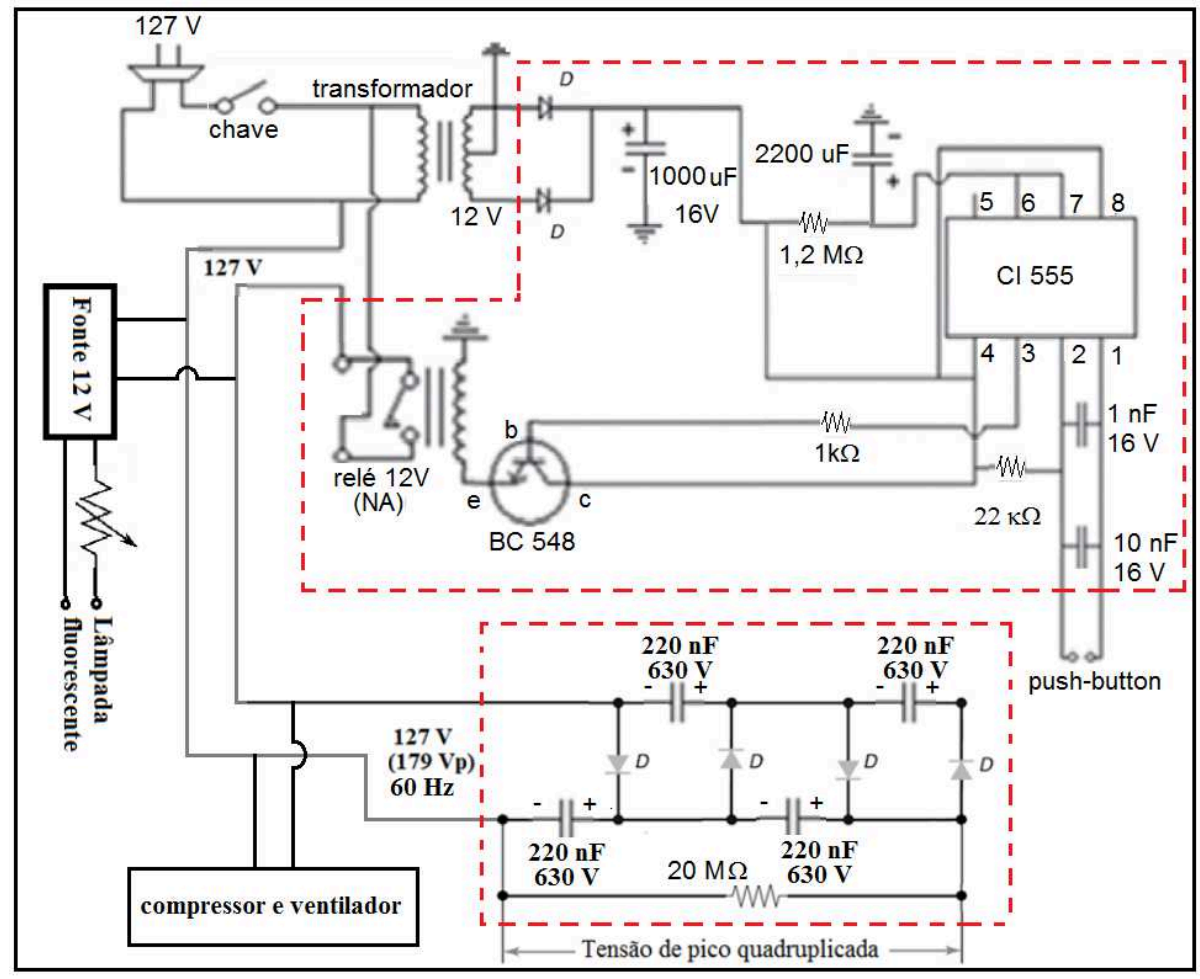

Fig. 2 - Diagrama esquemático da parte eletrônica. Fonte: Desenvolvimento alcançado por ideias em Malvino e Bates (2016).

Acerca do circuito multiplicador de tensão, que especificamente na Fig. 2 produz quatro vezes a tensão de pico de entrada, alcançando $720 \mathrm{Vcc}^{19}$, por comparação, uma câmara de neblina de difusão comercializada (com refrigeração por dispositivo termoelétrico peltier) de região circular de observação de traços com diâmetro de $15 \mathrm{~cm}$, estabelece uma fonte de alimentação embutida de alta voltagem da ordem de $800 \mathrm{Vcc}$, no objetivo de limpeza de íons indesejados segundo um fabricante ${ }^{20}$. Essa diferença de potencial de $720 \mathrm{Vcc}$ é estabelecida nessa montagem conectando o terminal positivo na chapa de cobre (Fig. 1B) e o terminal positivo na grade superior da câmara (Fig. 1C).

\footnotetext{
19 Pulsante.

$20<$ https://www.pasco.com/prodCompare/diffusion-cloud-chamber/index.cfm>.
} 


\section{II.3 Preparação final e aplicação}

Recomenda-se, nesta etapa final, a preparação de uma caixa (madeira ou acrílico) com dimensões apropriadas para abarcar os detalhes anteriores tanto por uma questão de acabamento quanto pela mútua proteção equipamento/visitante ${ }^{21}$, de modo a ficarem as peças elaboradas, impossibilitadas de se tornarem alvo de contatos físicos em casos de 'curiosidades' indevidas. A Fig. 4A, mais adiante, apresenta uma foto do equipamento na área de exposição pública do Museu de Ciência e Tecnologia da instituição onde se encontra a autoria do trabalho, já há alguns meses em funcionamento. Particularmente aqui, deixou-se aparente o ventilador de um lado da caixa, cuja ventilação que atravessa a grade do condensador sai por uma tela adaptada no lado oposto, podendo o equipamento ficar imóvel num suporte em parede ou com rodinhas para locomoção, prevalecendo sensatez de deixá-lo em lugar de menor claridade possível para auxiliar a visualização de traços pela iluminação da própria câmara.

Havendo dois botões expostos ${ }^{22}$, o equipamento fica assim projetado para ser operado por um monitor/estagiário, incumbido, pouco antes da visitação agendada, de depositar uma quantia de $4 \mathrm{ml}$ de álcool isopropílico no feltro interno do vidro superior removível da câmara, assim fechando-a e logo acionando o botão após esse procedimento, mantendo acertada a intensidade luminosa da câmara diante a necessidade da baixa claridade externa na mesma. Ao ligar a câmara, os traços começarão a surgir após 15 minutos, tempo esse em que a superfície inferior se aproxima dos $30^{\circ} \mathrm{C}$ negativos, estabilizando mais à frente em quase $45^{\circ} \mathrm{C}$ negativos. Assim, a duração de uma demonstração permanece por quase 45 minutos, pois a programação eletrônica estabelecida desliga a câmara neste momento para, havendo demanda, se repetir o procedimento de depósito de álcool e prolongar a demonstração novamente. Todavia, frequentemente em dias úmidos, e após um tempo funcionando, indesejados embasamentos nas partes laterais inferiores e externas do vidro da câmara surgirão. Para evitá-los, sugere-se, com periodicidade e ao avaliar tal necessidade, a receita de esfregar um pano com mistura de álcool e detergente, em igual proporção, sobre toda a superfície externa do vidro da câmara. Um simples e rápido procedimento inicial desses manterá a transparência da câmera por dias.

Vale anexar na lateral frontal da caixa uma orientação do que observar com resumo explicativo. Em razão de o público visitante poder ser majoritariamente formado por estudantes do ensino básico e leigos em geral, os detalhes explicativos devem estar numa melhor linguagem compatível possível. A extensão e o nível desses detalhes podem, porém, ser julgados e aprimorados pela equipe pedagógica local, que ostenta a perspectiva seguida em espaços educativos não formais. Àqueles interessados em estruturar uma leitura deste tipo, mantendo

\footnotetext{
21 Os visitantes precisam estar seguros, incapazes de sofrerem acidentes como por choques elétricos diante inoportuna falha elétrica ou eletrônica.

22 Um para aperto (push-button NA), que aciona todo o funcionamento, e outro de girar (potenciômetro), que ajusta a intensidade luminosa.
} 
o espírito da proposta, segue, na Fig. 3, um modelo aqui pensado daquilo a ser anexado no equipamento para proveito e/ou guia nesse sentido.

\section{CAMARA DE NUVENS DE DIFUSÄO}

Observe o surgimento de traços aleatórios na superficie inferior da càmara. O que sâo eles?

Os chamados raios cósmicos não são raios, mas particulas (elètrons, prótons e núcleos complexos

de alta energia) que viajam através do universo e chegam ao nosso planeta. Ao colidirem com núcleos de atomos da atmosfera, a cerca de 10 mil metros acima da superficie da Terra, essas particulas dào origem a uma "chuva" de outras particulas (pions e múons) com menos energia, os chamados raios cósmicos secundários, cujo número delas que chegam ao nivel do mar, em média, é de uma particula por segundo em cada centimetro quadrado. Os raios cósmicos secundários são inofensivos à vida na Terra, mas os raios cósmicos primários são perigosos para os astronautas no espaço.

A câmara de nuvens é um interessante experimento pelo qual se evidenciam traços produzidos por essas particulas secundárias.

Como isso ocorre?

A condiçào é a seguinte: a supperficie inferior da càmara permanece a uma temperatura abaixo de $-30^{\circ} \mathrm{C}$; e um pouco de álcool é depositado no fel tro da tampa. Essa quantia de álcool, que evapora aos poucos do feltro, desce lentamente em direção à superficie inferior mais fria, na medida em que a càmara vai se saturando desse vapor. Nesse sistema, uma particula dessas, que por ele passar, ionizara o vapor supersaturado induzindo sua condensaçào em goticulas de álcool, formando um traço visivel do trajeto. Obviamente, não se vê particula alguma, mas o efeito de sua passagem naquele local, isto é, o traço então identificado.

Fig. 3 - Orientação com resumo explicativo. Fonte: os autores.

Conforme Gaspar (1993, p. 148), os visitantes, "na sua maioria, leem os textos apresentados pelo menos até que tenham uma ideia do objetivo ou proposta da demonstração". Com direcionamento ao público alvo, cabe ressaltar que cada texto em particular necessita então ser aprimorado a critério do aprofundamento estipulado na linguagem das explicações científicas em termos qualitativos ou não. Aliás, mesmo que qualquer preparação de leitura nesse sentido permaneça alvo de melhorias, é expressivo salientar que a essência dessa orientação explicativa, que se recomenda atrelar nos equipamentos, mantém-se conservada. Consequentemente, viabiliza-se que a experiência ali envolvida possa ainda ser "desencadeada" em momentos de interação entre visitantes ou por um processo de mediação ou visita guiada (FERREIRA; CARVALHO, 2016). Ressalta-se também, nesta perspectiva lúdica de interação com o equipamento, o papel auxiliador importante na prática pedagógica de professores da educação básica na medida em que os incentivam a relacionar as interações dos visitantes com o trabalho feito na escola (BERNASIUK et al., 2009, p. 1). De acordo com Silva et al. (2013, p. 423), espera-se que esses fenômenos notados sejam posteriormente resgatados da memória de um estudante em situações de sala de aula onde um assunto abordado tenha sido por ele relacionado, permitindo o educador então usufruir de tais lembranças em melhoria do aprendizado dos conceitos científicos envolvidos no decorrer das discussões. 
No pequeno museu de ciências, que serve uma cidade de mais de 500 mil habitantes e demais cidades da região, há agendamentos de visitas gratuitas de turmas de alunos da educação pública e privada (nível médio e fundamental), com programação de atendimento de pouco mais de uma hora por turma no salão de exposição onde estão diversos aparatos interativos incluindo esta câmara de nuvens. Um monitor/estagiário, então, é orientado a repetir o procedimento de depósito de álcool e acionar a câmara toda vez que uma nova turma entrar no salão. De modo rotineiro, iniciando às 8:00 horas, é refeito o processo mais três vezes até as 12:00 horas, situação prolongada de uso na qual resulta uma quantia significativa de álcool depositada no fundo da câmara. Para solucionar isso, entre o intervalo do matutino e vespertino, que vai das 12:00 às 14:00 horas, a tampa da câmara permanece aberta para a evaporação do álcool, que assim permite uma nova condição inicial procedendo então das 14:00 horas até as 18:00 horas, final do expediente. A Fig. 4A apresenta uma foto de interação dos visitantes com o equipamento. Já na Fig. 4B, há uma seleção de imagem de traços visíveis em pause de uma filmagem da lateral oposta à da iluminação.

\section{Considerações finais}

Nos ambientes de educação não formal, onde as visitações são diárias e as demonstrações devem se manter reprodutíveis com a maior segurança e praticidade possíveis, câmaras de nuvens de difusão projetadas com gelo seco somente são viáveis com a disponibilidade de um 'freezer de ultra baixa temperatura' no local, para garantir a necessária manutenção de troca dessa substância no sistema por um monitor em cada demonstração de nova visita no salão de exposição. De outra forma, a aquisição diária de gelo seco (ou nitrogênio líquido), no mercado para tal atividade demanda certo custo mensal e não descarta a manutenção do sistema, isto é, a reposição dessa substância na refrigeração da câmara. Em geral, as propostas de montagens mais simples com pastilha termoelétrica Peltier descartam a aquisição dessas substâncias, mas apresentam pequenas áreas de observação de traços que não tanto promovem a visualização dos mesmos quando suas origens forem da radiação cósmica, além de limitar menor número de observadores ao seu redor. Já com distinto princípio de refrigeração e também aos fins educacionais, mencionaram-se os elevados custos de sofisticadas câmaras de neblina de difusão, que, no presente contexto, atendem os desejados requisitos: melhora da área de observação dos traços de partículas; resolve o problema da manutenção da refrigeração do sistema; aumenta o tempo de duração da demonstração. Consentindo que com tais preparativos melhor se viabiliza uma adaptação desse tipo de demonstração num museus de ciências (e ambientes similares), este trabalho procurou contribuir com uma proposta acessível e diferenciada de montagem que considera esses requisitos ao seguir a aplicação discutida anteriormente, e que possa então vir a ser proveitosa aos profissionais interessados. Cabe mencionar 
que o custo total desta proposta de montagem, reunindo as peças e produtos utilizados com gastos mais significativos ${ }^{23}$, estimou-se não ultrapassar o valor de 1000 reais.

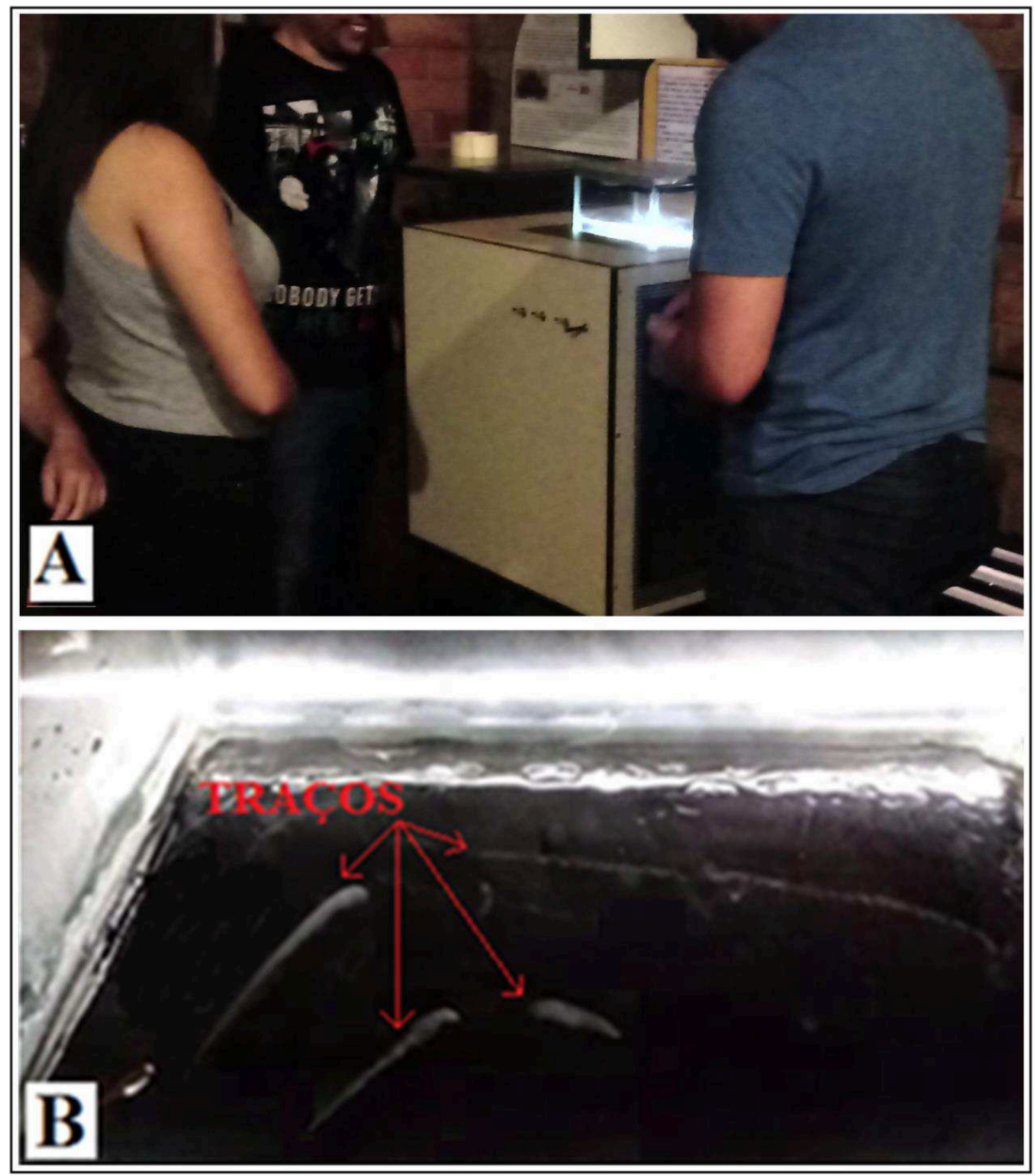

Fig. 4 - A) Câmara de nuvens operando mediante visitação; B) Típicos resultados observados. Fonte-autores.

Por fim, cabe uma reflexão de montagem a respeito do equipamento aqui desenvolvido e testado como um protótipo, com área retangular de observação de $300 \mathrm{~cm}^{2}$. Este protó-

23 Compressor (270 reais), gás (40 reais), mão de obra da carga de gás (80 reais), chapa de cobre e silicone (50 reais), circuitos eletrônicos e fiações diversas (70 reais), estrutura de madeira/caixa (120 reais), ventilador (70 reais), chapas de vidro e silicone (60 reais), tinta spray preto fosco (20 reais), lâmpada fluorescente de Scanner (40 reais). 
tipo serve de guia para posteriores reproduções de câmaras com áreas maiores, dimensionadas com serpentinas espirais mais compridas abaixo de chapas metálicas maiores ao empregar até mesmo um compressor mais potente, compatível com gás refrigerante R-404A. Aliás, para uma montagem de maior complexidade, um aprimoramento diferenciado poderia considerar adaptar um sistema automatizado para o fluxo de álcool, capturando o excedente do fundo da câmara para um gotejamento controlado em canaletas localizadas na região superior, o que reduziria, assim, a manutenção periódica comentada nesse sentido. Contudo, embora essa solução seja interessante, não torna obrigatória à viabilidade da proposta abordada, uma vez que monitores são comumente utilizados nos salões de exposição para eventuais direcionamentos, atendimentos ou esclarecimentos extras e, inclusive, auxílio no zelo dos equipamentos, tendo a incumbência de abastecer periodicamente com álcool o equipamento; procedimento este muito simples de ser realizado e que dispensa diminuto tempo. Aliás, além de a presente proposta de montagem ser útil também aos laboratórios didáticos de universidades, profissionais da educação básica (física e química) podem igualmente aderi-la, uma vez que o presente trabalho nesse contexto converge para a recomendação de Arqüello (2001), expondo a necessidade de desmistificação da sofisticação existente nos equipamentos de museus de ciências (sejam eles comprados ou lá fabricados) para que eles possam ser reproduzidos inclusive nas escolas.

\section{Referências}

ARQÜELLO, C. A. In: Educação para a ciência: curso para treinamento em centros e museus de ciência. São Paulo: Editora Livraria da Física. 2001, p. 145-148.

BERNASIUK, M. E.; BORCELLI, A. F.; AURICH, N. K. Atividades interativas e suas contribuições para o ensino de Física. In: SIMPÓSIO NACIONAL DE ENSINO DE FÍSICA, XVIII, 2009, Vitória, ES. Atas...

CÂMARA DE NUVENS PARA DETECTAR PARTÍCULAS CÓSMICAS. Disponível em: <https://www.youtube.com/watch?v=KsPIFFEiCc8>. Acesso em: 19 fev. 2018.

CHELINI, M. E.; LOPES, S. G. B. C. Exposições em museus de ciências: reflexões e critérios para análise. Anais do Museu Paulista, v. 16, n. 2, p. 205-238, jul-dez, São Paulo, 2008.

DENTILLO, D. B. Centros e museus crescem, mas investimento ainda é insuficiente. Ciência e Cultura, São Paulo, v. 65, n. 2, p. 12-13, abr./jun. 2013.

DIERKING, L. D. Lessons without limit: how free-choice learning is transforming science and technology education. História, Ciências, Saúde - Manguinhos, v. 12 (supplement), p. 145-160, 2005. 
FERREIRA, G. L.; CARVALHO, D. F. A ciência pode emocionar: a criação de um artefato interativo em um museu de ciências. Revista Fórum Identidades, v. 22, n. 22, jan./abr., p. 71-84, 2016.

GASPAR, A. Museus e Centros de Ciências: Conceituação e Proposta de um Referencial Teórico. 1993. Tese (Doutorado na área de Didática) - Faculdade de Educação, Universidade de São Paulo, São Paulo.

KAMATA, M.; KUBOTA, M. Simple cloud chambers using gel ic packs. Physics Education, v. 47, n. 4, p. 429-433, 2012.

LANGSDORF, A. A continuously sensitive cloud chamber. Physical Review, v. 49, p. 422, 1936.

MALVINO, A.; BATES, D. Eletrônica. 8. ed. AMGH Editora Ltda, 2016. v. 1.

MECONAL, S. G. Isothermally Heatsunk Diffusion Clould Chamber Refrigerator. United States Patent, Aug. 27, 1986.

NADA SCIENTIFIC. Peltier Cloud Chamber (SKU: N99-B10-7762). Disponível em: $<$ http://nadascientific.com/science_education/peltier-cloud-chamber.html>. Acesso em: 19 fev. 2018.

PASCO. Diffusion Cloud Chamber. Disponível em: <https://www.pasco.com/prodCompare/ diffusion-cloud-chamber/index.cfm>. Acesso em: 19 fev. 2018.

PHYWE. Cloud Chamber W Peltier Cooling (09043-01). Disponível em: <http://www.leermiddelen.be/en/cloud-chamber-wpeltier-cooling----phywe---09043-01>. Acesso em: 19 fev. 2018.

PHYWE. Diffusion Cloud Chamber (45 x45 cm PJ45). Disponível em: $<$ https://www.phywe.com/en/diffusion-cloud-chamber-45-x-45-cm-pj45.html>. Acesso em: 19 fev. 2018.

PHYWE. Diffusion Cloud Chamber (80 x 80 cm, PJ80, 230V). Disponível em: $<$ https://www.phywe.com/en/diffusion-cloud-chamber-80-x-80-cm-pj-80-230-v.html>. Acesso em: 19 fev. 2018.

PINHEIRO, L. A. A câmara de nuvens: uma abordagem integrada entre a Física Clássica e a Física Moderna. Caderno Brasileiro de Ensino de Física, v. 32, n. 2, p. 517-528, ago. 2015.

SILVA, O. H. M.; ARRUDA, S. M.; LABURÚ, C. E.; BUENO, E. A. S. Pêndulo de Wilberforce: uma proposta de montagem para ambientes educativos informais e laboratórios didáticos. Caderno Brasileiro de Ensino de Física, v. 30, n. 2, p. 409-426, ago. 2013. 
STONG, C. L. The amateur scientist: how to fit a diffusion cloud-chamber with a magnet and other accesories. Scientific American, p. 173-184, jun, 1959.

VALENÇA, V. L. C. A criação do Museu das Crianças de Santa Catarina: uma experiência em andamento. Perspectiva, v. 24, n. 1, p. 319-338, jan/jun 2006.

WILSON, C. T. R. On a Method of Making Visible the Paths of lonising Particles through a Gas. In: Proceedings of the Royal Society of London. Series A. Containing Papers of a Mathematical and Physical Character, v. 85, n. 578, p. 285-288. Published by: Royal Society, jun. 9, 1911.

WILSON, C.T.R. On an expansion apparatus for making visible the tracks of ionising particles in gases and some results obtained by its use, Philosophical Transactions of the Royal Society A.87, p. 277-292, 1912. 